\title{
Investigate the relationship between academic achievement and emotional intelligence and quality of life in Bam University of Medical sciences-20I5
}

\begin{abstract}
Background: This Study was aimed to study association of Motivation Academic Achievement with Emotional Intelligence and Life Quality of female Students of Bam University of Medical Sciences-2015.

Materials and methods: This cross sectional descriptive-analytical study was conducted using the stratified random sampling, which 188 female undergraduate students of Bam University of Medical Sciences, in the academic year 2015 were selected. Research instruments were Hermen's achievement motivation questionnaire and emotional intelligence test Bradbry-Graves and Sf-36. To analyze data, T-test, Anova, Pearson and regression analysis were used by using SPSS version 20 .

Results: There were no significant differences between the variables of academic achievement motivation, emotional intelligence and quality of life in terms of demographic variables. Despite a significant relationship between the motivation of academic achievement and quality of life and emotional intelligence, regression analysis results showed that there was no significant correlation between the motivation of academic achievement and quality of life and emotional intelligence.
\end{abstract}

Conclusion: The motivation for advancement is generalizable and training, so training courses for motivation development can be very helpful in this.

Keywords: motivation of academic achievement, quality of life, emotional intelligence
Volume 7 Issue 2 - 2018

\section{Rahil Ghorbani Nia}

Health Services Management Research Center, University of Medical Sciences, Iran

Correspondence: Rahil Ghorbani Nia, Ph.D student, Health Services Management Research Center, Institute for Futures Studies in Health, Kerman University of Medical Sciences, Kerman, Iran, Tel 0939655857I,

Email r.ghorbani6790@gmail.com

Received: February 19, 2018 | Published: March 16, 2018

\section{Introduction}

Academic achievement in every society reflects the educational system's success in targeting and attention to individual needs. ${ }^{1}$ Research shows that factors and personal factors, social, cultural, economic, political, moral and psychological many academic growth can be effective. ${ }^{2}$ The concept of emotional intelligence in recent years in both fields and applied science, much attention is devoted to. ${ }^{3}$ This is due to high ability and emotional intelligence to solve problems and reduce conflicts between perceptions of thought and feeling. Numerous studies have shown that emotional intelligence can increase the health, prosperity, wealth, success, love and happiness. ${ }^{4}$ It also leads to better performance in four areas of self-awareness (understanding their capabilities and express them), social awareness (awareness of others and understand its capabilities and empathy), relationship management, and self-management (ability to adapt to change and solve problems personal and social). ${ }^{5}$ In terms of timeit ${ }^{1}$ Emotional intelligence is leading to mental health and, ultimately, success in education. ${ }^{6}$

Success in education at school and in later years on campus, with emotional skills, social and emotional intelligence as an incentive, the ability to wait, obey orders and impulse control skills to ask for help from others and express emotional needs and related training. Training students in all courses, in order to change behavior, thoughts, attitudes and skills they are done and finally for progress and academic performance is measured. ${ }^{8}$ So pay attention to the factors

${ }^{1}$ Bar on that contribute to motivation are of particular importance. ${ }^{9}$

The findings of some research and studies, explaining the role and importance of motivation in academic achievement. ${ }^{1}$ The success motivation achievement motivation or desire or passion success rate and participate in activities that their success depends on the efforts and ability of the person. Achievement Motivation plays an important role in motor learning and individual behaviors that lead to better and more effective learning. ${ }^{10}$ The role of health promotion as a factor in explaining the motivation arises and quality of life is one of the criteria for evaluating the health status has been introduced. A unique quality of life of every individual to understand his life, despite his relationship with family, friends and the community to how rewarding. ${ }^{11}$ In the study by scholars to the quality of life in motivation to study have noted and have found that factors such as health problems, economic problems, compromise, lack of social, lack of familiarity with the campus, away from family, lifestyle and quality of family relationships from below quality of life is considered to be a significant negative impact on their academic motivation. ${ }^{12}$ Fruit et al. ${ }^{13}$ and Parker et al. ${ }^{14}$ Showed that a significant relationship between total score of emotional intelligence and academic achievement there. But the Chinese Research processor and colleagues found that the overall score of emotional intelligence and academic achievement, there is no significant relationship. ${ }^{15,16}$ According to our educational system that is still in the ability of academic stress, and factors such as quality of life, learning and emotional intelligence as a set of attributes that are immeasurable in the fate of individuals are important, overlooked, the need for research this area is characterized, especially in most of the 
studies in this area to investigate these variables individually focused, so in this study, with regard to these three components together, this lack of coverage to be given.

\section{Materials and methods}

this study Sectional(Cross sectional) Descriptive analytical study where in The relationship between academic achievement and emotional intelligence and quality of life in female students of Medical Sciences Bam -2015 will be examined. Society the Research All students Bam University of Medical Sciences Mattress. TheL D.EdenD. After determining the sample size using cluster random sampling, 188 students were selected. Then distribute and collect forms, enter the questionnaires were analyzed. Inclusion criteria Participants in the study. Study time and interest to participate in a research study. Exclusion criteria included lack of cooperation in filling out the questionnaire and admits to not wanting to participate in the project. Questionnaires free time for individual students will be provided. Data were collected by questionnaire, which was set up in four parts, the first part of demographic characteristics including age, marital status, education, employment status and the subsequent emotional intelligence questionnaire Bradbry- Graves ${ }^{2}$, Quality of Life (SF-36) And achievement motivation was:

Emotional intelligence questionnaire bradburygraves (bradberi and greaves's emotional intelligence questionnaire)

In order to evaluate the students' emotional intelligence questionnaire of 28 items Graves ${ }^{3}$ emotional intelligence Bradbry(2005) to 4 scale Subsidiary Self-awareness (Question 16, Management (Question 7 - 13), Social Awareness (Question 14 20) And relationship management $(21-28)$ used. Test scoring method using 6-point scale. From 1 to 6 (Not always) with a maximum score of 160 and a minimum score of 28 (average score 94) is classified. scores more sign Donor Intelligence Emotional more was and Total score of subjects. Each One of REffectiveLG also account for the total test score The Leg The OrYi and Permissibly In the questionnaire. In 1385 by treasureThe Done. Reliability coefficients for the 4 skills formation The emotional intelligence and the total scores of 36 students for the conscious (73/0), Management (87/0), Social Awareness (78/0) and Relationship management (76/0) and total score of emotional intelligence (90/0) Report done SD. Ganji to determine the validity of the test, it comes with Emotional Intelligence test is performed in a group of 97 people. The correlation coefficient between them $68 / 0$ obtained, again in 99/0 level was significant. The reliability and validity of the test is approved. ${ }^{17}$

\section{Quality of life questionnaire (sf-36)}

Quality of life assessment tool Short Form Health questionnaire multidimensional which has 36 questions, the questionnaire examines the quality of life in eight areas, including physical function Limitations associated ${ }^{5}$ with $^{6}$ physical problems, Physical pain ${ }^{7}$ General health status, Vitality, ${ }^{8}$ Social Performance Restrictions in communicating

${ }^{2}$ Bradbury - Graves

${ }^{3}$ Bradbury - Graves

${ }^{4}$ Short Form Health Survey (Sf36)

${ }^{5}$ Physical Performance

${ }^{6}$ Limitations Associated with Physical Problems

${ }^{7}$ Physical Pain

${ }^{8}$ Vitality with mental problems And mental health Are. The quality of life in areas ranging from zero to one hundred scored. Higher scores indicate higher quality of life questionnaire was used first in America. And is translated in different languages. It Montazeri in Iran by the doctor and his colleagues designed in 1384 for the population. Internal consistency analysis showed that apart from the realm of vitality $(65 / 0=\alpha)$. Other areas of the Persian SF36The minimum standard ratios ranging from $77 / 0$ to $9 / 0$ respectively. The statistical test known groups comparison showed that the tool is able to differentiate the population by sex, age groups and is valid $58 / 0$ to $95 / 0 .{ }^{18}$

\section{Motivation questionnaire hermans (herman's academic achievement motivation questionnaire)}

Questionnaire 29 questions of achievement motivation (1970) for 29 , including incomplete stated that for every sentence incomplete four options given these options, depending on the intensity of motivation from high to low or low to high are they score the amount awarded. Scoring according to the characteristics of the 9 questions written on it, is carried out. This means that questions 29, 28, 27, 23, $16,15,14,10,9,4,1$ for (a) (1) (b) (2) (c) (3) (d) (4) and Questions $26,25,24,22,21,20,19,18,17,13,12,11,8,7,6,5,3,2$ (a) (4) (b) (3) (c) (2), (d) (1) are scored. High scores of questions that will Ydnd, showed a high individual achievement motivation and low scores are indicative of low achievement motivation. ${ }^{19}$ Reliability in 1393 by going door to Cronbach's alpha coefficient 70/0 were reported (25). ${ }^{20}$ FOR ETHICAL CONSIDERATION BEFORE FILLING OUT THE QUESTIONNAIRE, OPTIONAL UNIT OF PARTICIPATION IN A RESEARCH STUDY, THE CONFIDENTIALITY OF INFORMATION OBTAINED FROM THEM And Ajaz hkhrvj the subjects of study in any phase of the study was explained. The reluctance of students to complete the questionnaires of the limitations of this study. In order to solve this problem can be of assistance to teachers each department and group managers. Data After logging in, using software SPSS Version 20 spss And using descriptive and inferential statistical tests including tests TTest, Pearson correlation coefficient, Anova And significant linear regression analysis was used $05 / 0$.

\section{Results}

188 students of the study was to be completed, of which $147(2 / 78 \%)$ were single, 106 patients (4/56\%) students at undergraduate, 4/97 and $4 / 73 \%$ only student $\%$ of them were in the age group $22-18$. The average age of the students $51 / 0 \pm$ was $32.19 \%$ and a minimum of 18 and maximum of 37 years. Students studied demographic information listed in Table 1. According to independent t-test results in Table 2, the average values academic achievement, emotional intelligence and quality of life statistically significant difference between marital status, education, employment, education, employment status were observed (Table 2). Test results Anova Table 3 is provided. According to the table, it was found that a significant difference between academic achievement, quality of life and emotional intelligence by age group there (Table 3). To evaluate the correlation between the variables in the study of linear regression analysis were used. According to the results of regression analysis showed a significant correlation between the variables of achievement motivation and the quality of life there $(07 / 0=p, 68 / 1=F)$. Motivation Emotional Intelligence also failed to significantly predict students $(89 / 0=\mathrm{p}, 37 / 3=\mathrm{F})$. 
Table I Distribution of demographic characteristics of subjects.

\begin{tabular}{llll}
\hline Variable & & Number & Percent \\
\hline \multirow{2}{*}{ Employment status } & Only students & 148 & $4 / 97$ \\
& Practitioner & 40 & $6 / 2$ \\
Marital status & Single & 147 & $1 / 82$ \\
& Married & 41 & $9 / 17$ \\
Term time & Know-how & 82 & $6 / 43$ \\
& Masters & 106 & $4 / 56$ \\
Age category & $22-18$ & 138 & $4 / 73$ \\
& $27-23$ & 45 & $9 / 23$ \\
& $>28$ & 5 people & $7 / 2$ \\
\hline
\end{tabular}

Table 2 Comparison of quality of life, academic achievement and emotional intelligence among students about the research based on demographic data.

\begin{tabular}{|c|c|c|c|c|}
\hline Variable & & $\begin{array}{l}\text { Quality of } \\
\text { life }\end{array}$ & Motivation & $\begin{array}{l}\text { Emotional } \\
\text { intelligence }\end{array}$ \\
\hline \multirow{4}{*}{$\begin{array}{l}\text { Marital } \\
\text { status }\end{array}$} & Single & $15 / 23 \pm 83 / 144$ & 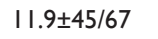 & $46 / 51 \pm 12 / 114$ \\
\hline & & $16 / 26 \pm 03 / 138$ & $72 / 6 \pm 83 / 65$ & $91 / 18 \pm 58 / 110$ \\
\hline & Married & & & \\
\hline & & $\mathrm{p}$-value $=0 / 58$ & $p$-value $=0 / 65$ & $\mathrm{p}$-value $=0 / 647$ \\
\hline \multirow{4}{*}{ Term time } & Know-How & $95 / 19 \pm 95 / 144$ & $59.6 \pm 03 / 69$ & $60 / 19 \pm 08 / 111$ \\
\hline & & $81 / 25 \pm 05 / 142$ & $97 / 9 \pm 66 / 65$ & $98 / 56 \pm 44 / 113$ \\
\hline & Masters & & & \\
\hline & & $\mathrm{p}$-value $=0 / 57$ & $\mathrm{p}$-value $=0 / 25$ & $\mathrm{P}$-value $=0 / 17$ \\
\hline \multirow{4}{*}{$\begin{array}{l}\text { Employment } \\
\text { status }\end{array}$} & $\begin{array}{l}\text { Only } \\
\text { students }\end{array}$ & $94 / 24 \pm 79 / 143$ & $15.7 \pm 76 / 67$ & $48 / 53 \pm 93 / 113$ \\
\hline & & $|4 / 7 \pm 50 /| 45$ & $70.9 \pm 25 / 66$ & $82 / 14 \pm 5 / 125$ \\
\hline & Practitioner & & & \\
\hline & & $p$-value $=0 / 5 \mathrm{I}$ & $\mathrm{p}$-value $=0 / 33$ & $\mathrm{p}$-value $=0 / 77$ \\
\hline
\end{tabular}

Table 3 Comparison of academic achievement, quality of life and emotional intelligence in the age group of subjects.

\begin{tabular}{lllll}
\hline & & Motivation & Quality of life & $\begin{array}{l}\text { Emotional } \\
\text { intelligence }\end{array}$ \\
\hline & $22-18$ & $40 / 9 \pm 9 / / 66$ & $21 / 15 \pm 68 / 143$ & $95 / 55 \pm 80 / 1 / 3$ \\
Age & $27-23$ & $36 / 6 \pm 27 / 68$ & $76 / 39 \pm 80 / 142$ & $52 / 20 \pm 77 / 109$ \\
category & & $50 / 10 \pm 60 / 62$ & $27 / 17 \pm 00 / 138$ & $17 / 49 \pm 43 / 112$ \\
& $>28$ & p-value $=0 / 34$ & P-value $=0 / 85$ & P-value $=0 / 74$ \\
\hline
\end{tabular}

Table 4 The relationship between academic achievement and quality of life and emotional intelligence subjects.

\begin{tabular}{lll}
\hline & Quality of life & Emotional intelligence \\
\hline \multirow{3}{*}{ Motivation } & $r=0 / 15$ & $r=0 / 73$ \\
& $p=0 / 024$ & $p=0 / 023$ \\
\hline
\end{tabular}

\section{Discussion}

This study aimed to determine the relationship between academic achievement and quality of life and emotional intelligence University students took Bam. According to the results, the mean score of academic achievement, emotional intelligence and quality of life were observed statistically significant differences in demographic variables. The results Farmer et al. there are different levels of education. In this ghazanfari and the Hashemite et al..$^{21}$ the demographic variables found no significant relationship with achievement motivation and quality of life. Results Consistent with results in line, which could be due to the fact that emotional intelligence, academic achievement and quality of life are learned that with proper training can improve and are motivated by personal circumstances and family depend. The relationship between academic achievement and quality of life and emotional intelligence results and a positive significant relationship between achievement motivation and quality of life and emotional intelligence showed. The findings on the relationship between emotional intelligence and academic achievement is inconsistent and inconclusive results cannot be withdrawn from them. Some research findings show that a positive and significant relationship between emotional intelligence and academic performance. ${ }^{22}$ And can be emotional intelligence as a predictor of academic achievement was remarkable. ${ }^{23}$ But the findings of other studies show that between emotional intelligence and academic achievement in the population of students there is no significant relationship. ${ }^{8}$

As for the relationship between achievement motivation and academic achievement this contradiction can be seen. For example, the findings of some studies show that between motivation and educational progress, there is a significant difference between male and female students in terms of achievement motivation meaningful way that motivation and academic achievement of girls than boys. ${ }^{24}$ But other studies show that there is no significant relationship between achievement motivation and academic achievement. ${ }^{25}$ The results Mansouri, farmer, god god Abadi et al. in line with the findings of the present study. When the person has the skills to control emotions and negative emotions, and also has the capabilities to create intrinsic motivation regardless of reinforcing the outer and the ability and communication skills recognized, the person in the learning environment has the ability and success of other people. ${ }^{26} \mathrm{In}$ other words, people who have a higher quality of life of achievement motivation will be higher and more healthy. Despite significant relationship between academic achievement and the quality of life and emotional intelligence, regression analysis showed a significant correlation between the variables of achievement motivation and the quality of life there. Emotional Intelligence also failed to predict students' academic achievement significantly. Results of desire oven. ${ }^{27}$ And Hussein Hussein a man and a $\operatorname{man}^{28}$ is consistent. But the Ylkylakan et al. ${ }^{29}$ stated that emotional intelligence can predict academic progress of students. The reason for this discrepancy could be the difference between the study groups.

\section{Conclusion}

The results of this study showed that between emotional intelligence, academic achievement and the quality of life there is no significant relationship that could be factors such as differences in the research community, cultural differences in learning. Generalized motivation and training, so training motivation can help a lot in it.

\section{Acknowledgments}

Deputy of Research and Technology of Kerman University of Medical Sciences for research funding (project number 940258) is sincerely appreciated. 


\section{Conflict of interest}

None.

\section{References}

1. Dortaj F, Zavaraki EZ, Aliabadi K, et al. The impact of distance education (based Mooc) on academic performance of PNU. Quaterly Journal of Research in Educational Systems. 2017;10(35):1-20.

2. Saedi Z, Farahbakhsh K. Relation among Quality of Life, Life Style, Academic Performance with Academic Achievement in Isfahan University of Medical Sciences student's. Educ Strategy Med Sci. 2016;9(3):176-185.

3. Sobhi GN. The prediction of achievement motivation from students emotional intelligence. Journal of school psychology. 2012;1(3):49-62.

4. Alizadeh S, Namazi A, Kochakzadeh TS. Student, Educational achievement, self-esteem, emotional intelligence. Research in Medical Education. 2014;6(1):1-9.

5. Bahrami N, Najafvand DS, Bahrami S, et al. The Status of Emotional Intelligence and its Association with Demographic Variables among Students of Dezful University of Medical Sciences in 2013. Jundishapur Scientific Medical Journal. 2015;14(3):283-292.

6. Bar OR. Emotional intelligence: an integral part ofpositive psychology. South African Journal of Psychology. 2010;40(1):54-2.

7. Keshavarz N, Amini M, Mani A, et al. A study on the relationship between emotional intelligence and academic achievement in students of Shiraz University of Medical Sciences. Media. 2014;5(3):70-77.

8. Sharfi N, Ganji H, Hashemian K, et al. Comparison Of Cognitive Intelligence, Creativity \& Emotional Intelligence In Predicting Academic Achievement of Students. Journal of Psychologyin Industry \& Organization. 2012;2(6):17-29.

9. Hosseini M, Dejkam M, Mirlashari J. Correlation between academic achievement and self-esteem in Rehabilitation Students in Tehran University of SocialWelfare \& Rehabilitation. Iran $J$ Med Educ. 2007;7(1):137-42

10. Kharaem AR, Narimani M, Kharaem AS. A comparison of self-efficacy beliefs and achievement motivation in students with and without learning disability. Journal of Learning Disabilities. 2012;1(3):85-104.

11. Yeganeh T, Soltani SR, Kafi SM, et al. The Relationship between Emotional Intelligence, Time Management and Quality of Life with Academic Achievement among Students. J Rafsanjan Univ Med Scie. 2013;12(3):219-32.

12. Unalan D, Celikten M, Soyer F, et al. Quality of life in turkish university students and its relationship to levels of state-trait anxiety. $J$ Social Behavior and Personality. 2008;36(3):417-24.

13. Samari AA, Tahmasebi F. The study of correlation between emotiona intelligence and academic achievement among university students. Fund Ment Health. 2008;9(3635):121-8.

14. Parker JDA, Summerfeldt LJ, Hogan MJ, et al. Emotional intelligence and academic success: Examining the transition from high school to university. Pers Individ Differ. 2004;36(1):163-72.
15. Chinipardaz Z, Boroujerdni GM, Pasalar P, et al. Investigation of emotional intelligence and its relationship with academic achievement in medical students of Tehran University of Medical Sciences in 2008-2009. Strides Dev Med Educ. 2012;8(2):167-72.

16. Bar-On R. The Bar-on model of emotional social intelligence. Psicothema. 2006;18:45-49.

17. Ganji H, Mirhashemi M, Sabet M. Bradberry- Greaves' Emotional Intelligence Test: Preliminary Norming-Process. Applied psychology. 2006;1(2):23-35

18. Motamed N, Ayatollahi AR, Zare N, et al. Validity and Reliability of Persian Sf-36 questionnaire. East Mediterr Health J. 2005;5(1):49-56.

19. Kadivi A, Vakili MA. A Survey of relationship between achievement motivation, locus of control, self-concept and high school first grader science students academic achievement the five regions of Tabriz. Journal of instruction and evaluation. 2011;4(13):45-66.

20. Dorri GR, Miri MR. Abs the Relation between Self-efficiency and Emotional Intelligence with Achievement Motivation amongUniversity Students. J Health Syst Res. 2015;11(2):258-266.

21. Ghazanfari F, Hashemi S. The study of relationship between quality of occupational life and progress motivation in health team of Ashayer hospital in Khorramabad. Journal of Clinical Nursing and Midwifery. 2017;6(1):30-39.

22. Talebzade NM, Norouzi AA. The relationship between emotional intelligence and metacognitive awareness of reading strategies with academic performance of Students in the Department of Educational Sciences, Shahid Beheshti University. Journal of Scientific-Research new Approach in The Management of Islamic Azad University Shiraz. 2012;2(2):1-22.

23. Fayombo GA. Emotional Intelligence and Gender as Predictors of Academic Achievement among Some University Students in Barbados. International Journal of Higher Education. 2012;1(1):102-111.

24. Necla KH. An Investigation of the relationship between motivation and academic achievement of business administration students: An empirical study in Turkey. European Journal of Social Sciences. 2012;30(4):612617.

25. Ergene T. The relationships among testanxiety, study Habits, achievement motivation, and academic performance among Turkish High School Students. Education and Sciences. 2011;160(36):320-330.

26. Izadi Yazdan AA, Abolghsemi M, Mirali RO. The Relationship between Emotional Intelligence \& Academic Achievement in Student of Military University. Journal of Military Psychology. 2011;2(5):17-27.

27. Tammanaee FM, Gandomi Z. Relationship between achievement motivation and academic achievement of students. Educational Strategies Journal. 2012;4(1):15-19.

28. Hossein Mardi AA, Hossein MZ. Prediction of academic achievement based on emotional intelligence and achievement motivation among students of Islamic Azad University of Roudehen branch in 2013. Pajouhan Scientific Journal. 2015;13(3):15-22.

29. Yelkikalan N, Hacioglu G, Kiray A, et al. Emotional intelligence characteristics of students studying at various faculties and colleges of universities. European Scientific Journal. 2012;8(8):33-50. 